\title{
Development of Soil Bin for Model Studies on Furrow Openers
}

\author{
Mithlesh Kumar*, Ravi Baghel and Toman Parihar \\ Indira Gandhi Krishi Viswavidyalaya, Raipur, Chhattisgarh, 492012, India \\ *Corresponding author
}

\section{A B S T R A C T}

\begin{tabular}{|l|}
\hline Ke y w o r d s \\
$\begin{array}{l}\text { Soil bin, Furrow } \\
\text { openers, Draft, Soil } \\
\text { disturbance. }\end{array}$ \\
\hline Article Info \\
\hline $\begin{array}{l}\text { Accepted: } \\
\text { 21 October } 2017 \\
\text { Available Online: } \\
\text { 10 December } 2017\end{array}$ \\
\hline
\end{tabular}

The experiment was aimed to develop an indoor soil bin for testing a furrow opener under simulated condition in BRSM College of Agricultural Engineering and Technology, Mungeli, Chhattisgarh, India. The seedbed for testing furrow openers was prepared by hammering and compactor tool. Two types of sliding furrow openers are selected for study are inverted ' $\mathrm{T}$ ' and shovel type furrow opener in soil bin. The forward speed of operation was measured $1.8 \mathrm{kmph}$. Moisture content and bulk density of soil bed was measured $21.54 \%$ and $1.82 \mathrm{~g} / \mathrm{cm}^{3}$. Draft was found to be $22 \mathrm{kgf}$ and $37 \mathrm{kgf}$ at the depth of 75 and 100 $\mathrm{mm}$ for inverted ' $\mathrm{T}$ ' type furrow opener. In case of shovel type furrow opener it observed $18 \mathrm{kgf}$ and $35 \mathrm{kgf}$ at 75 and $100 \mathrm{~mm}$ depth. The soil disturbance by inverted ' $\mathrm{T}$ ' type furrow opener was observed $168 \mathrm{~mm}$ and $230 \mathrm{~mm}$ at operational depth of 75 and $100 \mathrm{~mm}$. Whereas in case of shovel type furrow opener it was observed to be 156 and $150 \mathrm{~mm}$ at 75 $\mathrm{mm}$ and $100 \mathrm{~mm}$ depth respectively.

\section{Introduction}

There have been may intensive researches done for better understanding soil -tillage tools interaction due to complex problem between the various devices, tillage tools, devices etc. on various conditions of soil. The tests are conducted either on soil bin found in indoor testing facilities or by performing real field testing. Usually, the soil parameters in soil bins such as variation of cone index and soil compaction level are more constant (Naderi et al., 2009). Generally, a soil bin facility consists of soil bin, tool carriage, drive system, instrumentation and data acquisition systems. Stephens et al., (1991) conducted a soil bin test to measure the soil strength in and around the seed zone of several planting systems operated over a range of adjustments and soil conditions.
Primary and secondary soil manipulation is the basic operation required for cultivation of any kind of crop. The conventional mode of agriculture through intensive agricultural practices was essential in achieve goals of production but simultaneously led to degradation of natural resources. Gupta, et al., (1991) found that the spiral cutting edge tine gave about $9.13 \%$ higher performance index than the straight edge tine under wet land conditions. Sharma, et al., (1984) compared the effect of a no-tillage system with conventional tillage in relation to various aspects and found that there was no significant difference between the infiltration rates, bulk densities and average yields. Moisture retention, available moisture and moisture depletion during stress periods were 
high in no-tillage treatment. The no-tillage system required less energy and production costs were approx. 1.5 times lower than in the conventional system. Alternative tillage system such as zero tillage, minimum tillage, no till, strip till was created in direction to minimize machinery interference with the soil. The placement of seed at shallow depth at residual moisture zone increases the productions. Furrow opener of any seeding and planting machinery plays an important role in placements of seeds at uniform depth and spacing. A net groove in the moist soil zone with minimum soil disturbance avoids mixing soil at seed level. Mathur, (1992) studied the influence of system parameters on the performance of a reversible shovel furrow opener for animal-drawn seed drills. The experiments were conducted in an indoor soil bin filled with lateritic sandy loam soil, at 4 rake angles (20, 25, 30, 35 degrees), 4 working depths $(50,75,100,125 \mathrm{~mm})$ and 3 forward speeds $(0.37,0.77$ and $0.90 \mathrm{~m} / \mathrm{s}$ ). Seed emergence tests were also conducted in the soil bin. The average seed germination was found to be $80 \%$.The drought requirement of machinery/implements was a function of soil property tool geometry, working, depth, travel speed and width of the implements. Larson, et al., (1993) conducted tillage tests in a laboratory soil bin to quantify the draft force and tillage energy reductions obtained with electro osmosis. Tests were conducted in loam and clay loam soils at two moisture contents each at tillage speeds of 3.3 to $7.7 \mathrm{~kg} / \mathrm{h}$. Shen et al., (1993) conducted a study on three different model tillage blades i.e. Rectangular Flat Blade (REFB), SemiCircular Flat Blade (SCFB) and SemiCircular Concave Blade (SCCB) and to evaluate the draught requirements of the tillage blades under different operating conditions. Drought and power requirements are important parameters for measuring and evaluating performance of machinery/ implements. The wider furrow openers creates excessive soil disturbance and soil furrow with the effect of increasing the depth of soil cover on adjacent furrows, increasing simulations of wheel speed germination and enhancing seedbed soil moisture loss. Tajuddin et al., (1995) evaluated hoe, shoe, wedge, single disc and double disc types of furrow opener in the field. The single disc furrow opener had the highest performance index and lowest unit draught among the furrow openers compared (Chowdhari, 2001). In wider furrow opener pre-emergence weedicide often machinery incorporated by sowing operation as well as excess lateral soil throw at seeding can result in herbicides contaminated soil reaching adjacent seed rows. The furrow openers with narrow points reduce soil disturbances and soil furrow results in reduction in soil moisture loss. Furrow opener is an important component of sowing machinery. The common type of furrow openers that used on seed drill are shoe, hoe, shovel, inverted T-type, disc type openers. The furrow characteristics influence the germination and emergence of crop under different soil conditions. These characteristics are compaction in the furrow, planting depth, draft power and operational speed. Increase in the depth of furrow opener increase the draft force and often recovering of soil in the furrows. Performance evaluation of various types of furrow openers has been studied by several researches. The results showed that the characteristics furrow openers have affected soil parameters, the draft force, seed distribution, plant emergence and plant growth. Chi et al., (1989) analysized different blades to simulate soil cutting with a flat and a triangular blade. The results of the analysis were verified by a laboratory cultivation test in the soil bin and found that finite element analysis provided accurate prediction of draught force. Dwyer et al., (1988) tested the tractive performance of full-size wheels under paddy field conditions in outdoor soil bin. Tests were carried out on a conventional 
tractor driving wheel tyre, a tyre and retractable strake, an open-lug cage wheel and a low pressure tyre. All wheels and tyres produced satisfactory thrust, except for the low pressure tyre. The rolling resistance was very high in all cases, so that none of the wheels or tyres was able to achieve a tractive efficiency of more than 30\% (Chowdhari, 2001). Durant et al., (1979) tested rotary cultivator in soil bin with a soil processing carriage supporting a rotary cultivator, a blade for leveling the soil and a roller, as well as a tool carriage with a dynamometer, to test tillage tools under dynamic loading conditions. The main objective of this paper is to develop a soil bin for model study of furrow openers and to study effect of sliding i.e. inverted ' $T$ ' type and shovel type furrow opener on draft requirements and soil disturbance.

\section{Materials and Methods}

\section{Development of soil bin}

The soil bin test set up was fabricated in workshop of BRSM College of Agricultural Engineering and Technology, Mungeli, to study the performance of different types of furrow openers under simulated conditions Figure 1. The soil bin was completely filled with black soil. It consists of rectangular soil bin, tool carriage, drive system etc. The size of soil bin was decided $(\mathrm{L} \times \mathrm{W} \times \mathrm{H}) 5000 \times$ $940 \times 200 \mathrm{~mm}$ to proper working of a unit of different furrow opener on soil bin. Drive system was designed for bullock drawn implement at speed varies from 1.5 to 2 $\mathrm{kmph}$. The motor provided $1440 \mathrm{rpm}$ which is reduced at $48 \mathrm{rpm}$ through reduction unit of 30:1. According to this the diameter of drum was decided $220 \mathrm{~mm}$. It provided about 1.8 $\mathrm{kmph}$ speed to the to the implement carriage through metalrope. There were two types of furrow opener Inverted ' $T$ ' and Shovel type furrow opener used for evaluating draft and soil disturbance (Figure 2).

\section{Moisture content}

Moisture content of soil on percentage wet basis was calculated as follows

M.C. $(w b \%)=\frac{W 1-W 2}{W 1} \times 100$

Where,

$\mathrm{W} 1=$ wt. of wet soil, gm

$\mathrm{W} 2=$ wt. of dry soil, gm

\section{Bulk density}

The bulk density was determined by dividing the weight of sample by volume it occupied and calculated by using the formula.

$\rho=\frac{\mathrm{m}}{\mathrm{v}}$

Where,

$\rho=$ Bulk density of soil, $\mathrm{g} / \mathrm{cm}^{3}$

$\mathrm{m}=$ Mass of soil contained in core sampler, $\mathrm{g}$

$\mathrm{v}=$ Volume of core sampler, cubic $\mathrm{cm}$

\section{Draft force measurement}

A $10 \mathrm{~mm}$ diameter steel pipe rope was to pull the furrow opener and test trolley. One end of the rope was attached to the spring dynamometer (capacity $100 \mathrm{kgf}$ ) and the other end after passing through over cylindrical drums (220 mm diameter and $900 \mathrm{~mm}$ length) was fixed to the test trolley.

For moving the test trolley along the bin, a rope drum drive arrangement was installed. The draft force for pulling the furrow opener and test trolley was measured by spring dynamometer connected between the trolley and the rope. The draft force required to pull the furrow opener was measured by the spring 
dynamometer having least count $1 \mathrm{~kg}$ was an average deflection of the indicator gave the direct reading of the force acting on the furrow opener (Figure 3).

\section{Measurements of soil disturbances}

The Measurements of soil disturbances caused by the different furrow openers for developed test soil bin.

In the soil bin, the soil disturbance was measured for each test and each furrow opener to measuring the soil disturbance on $200 \mathrm{~mm}$ long square of lime powder. After passing of the opener from lime square, the positions of lime powder across the line of travel of opener was measured with the help of a scale.

\section{Results and Discussion}

\section{Effect of tool geometry on draft}

The two types of sliding furrow openers as Inverted ' $\mathrm{T}$ ' type and narrow shovel are tested in a soil at two varying depth as $75 \mathrm{~mm}$ and $100 \mathrm{~mm}$. The moisture content of soil was $21.54 \%$ (wb) and bulk density was 1.82 $\mathrm{g} / \mathrm{cm}^{3}$. The speed of operation was constant as $1.8 \mathrm{kmph}$.

The draft of implement was found to be increased with depth of operation. It was found to be varied 20 to $25 \mathrm{kgf}$ at the depth of $75 \mathrm{~mm}$ and 35 to $40 \mathrm{kgf}$ at the depth of 100 $\mathrm{mm}$ for inverted ' $\mathrm{T}$ ' type furrow opener.

Similarly in case of shovel type furrow opener it was found to be also increased with depth of operation. It was found to be 15 to $20 \mathrm{kgf}$ at the depth of $75 \mathrm{~mm}$ and 30 to $40 \mathrm{kgf}$ at the depth of $100 \mathrm{~mm}$ for narrow shovel type furrow opener (Figure 4 and 6). The result shows that as the depth increased draft is also increased for both furrow openers.

\section{Effect of tool geometry on soil disturbance}

The speed of operation was constant as 1.8 $\mathrm{kmph}$. The soil disturbance by inverted " $\mathrm{T}$ " type furrow was found to be also increased with depth of operation. It was found to be160, 170, 180, 165 and $165 \mathrm{~mm}$ at different place at the depth of $75 \mathrm{~mm}$, so average soil disturbance was found to be $168 \mathrm{~mm}$; and at the depth of $100 \mathrm{~mm}$ it was found to be 200 , 225, 250, 225 and $250 \mathrm{~mm}$ at different place, so average soil disturbance was found to be $230 \mathrm{~mm}$. Similarly in case of the shovel type furrow opener the soil disturbance was found to be $150,160,160,160$ and $150 \mathrm{~mm}$ at different place at the depth of $75 \mathrm{~mm}$, so average soil disturbance was to be found 156 $\mathrm{mm}$; and the depth of $100 \mathrm{~mm}$ it was found to be $150,125,150,150$ and $175 \mathrm{~mm}$ at different place, so average soil disturbance was found $150 \mathrm{~mm}$ by shovel type furrow opener (Figure 5 and 7). It is observed that draft force and soil disturbance in case of inverted ' $\mathrm{T}$ ' type furrow opener was greater as compare to shovel type furrow opener; because working width of inverted ' $\mathrm{T}$ ' type furrow opener was greater due to the boot was attached with it.

Indoor soil bin experiment was conducted with the view to determine the effect of width and working depth on the draft and soil disturbance of the tillage implement used for seed bed preparation in black soil. A laboratory test shows that soil bin condition were in good working range for tillage operation of two sliding type furrows as inverted ' $\mathrm{T}$ ' type and shovel type at two varying depth. From the study it was concluded that draft of implement increased with the increased with the depth of operation where heavier draft was ' $T$ ' type as compared to narrow shovel type furrow opener. The soil disturbance was maximum in inverted ' $T$ ' type furrow opener than as compared to narrow shovel type furrow opener. 
Fig.1 Experimental soil bin test set-up

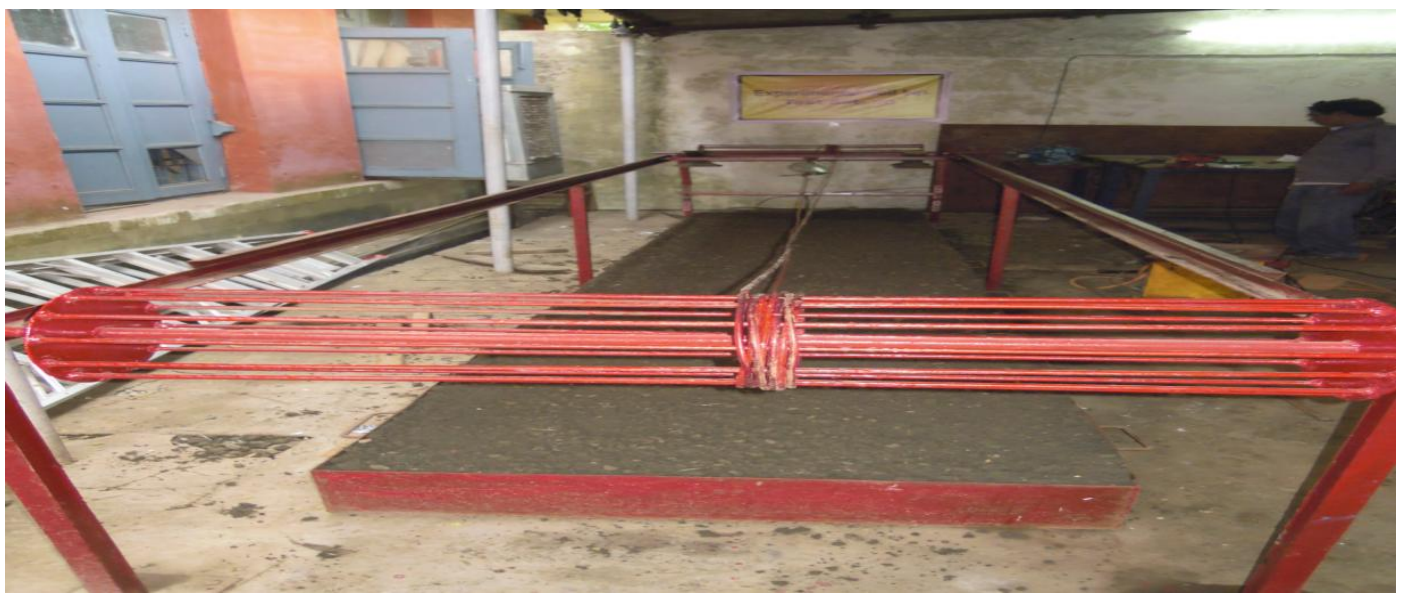

Fig.2 Inverted ' $\mathrm{T}$ ' and Shovel type furrow opener working on soil bin

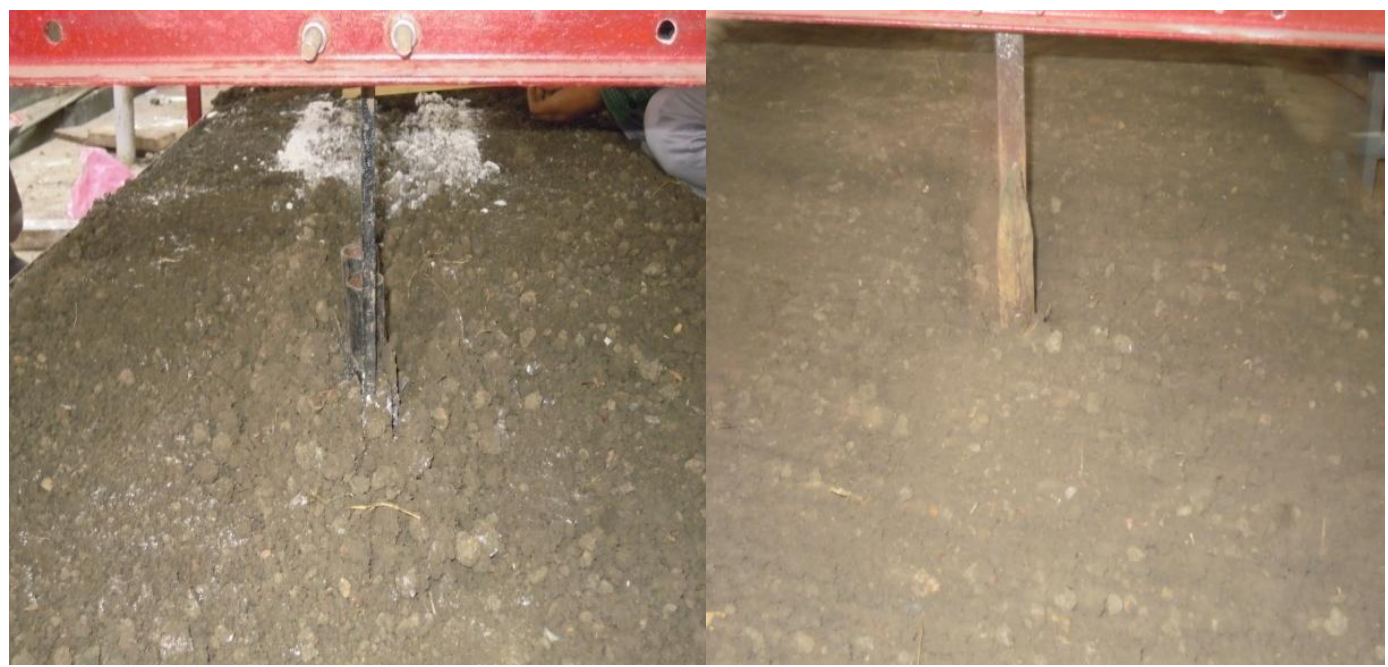

Fig.3 Measurement of draft and soil disturbance in soil bin

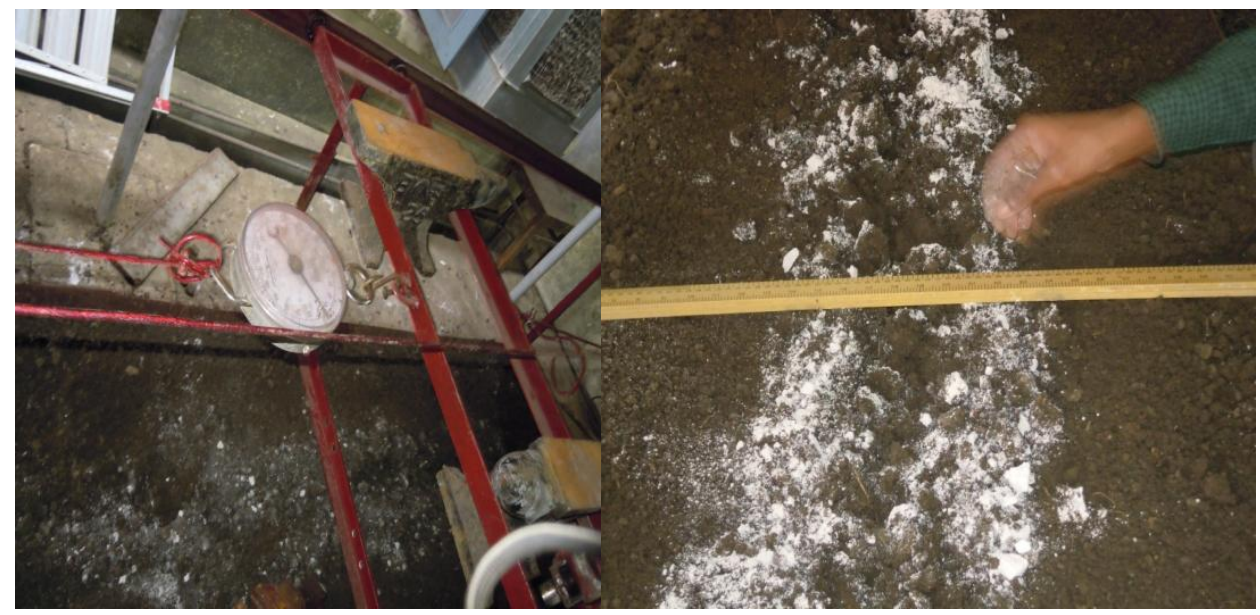


Fig.4 Effect of depth on draft for inverted ' $\mathrm{T}$ ' type furrow opener

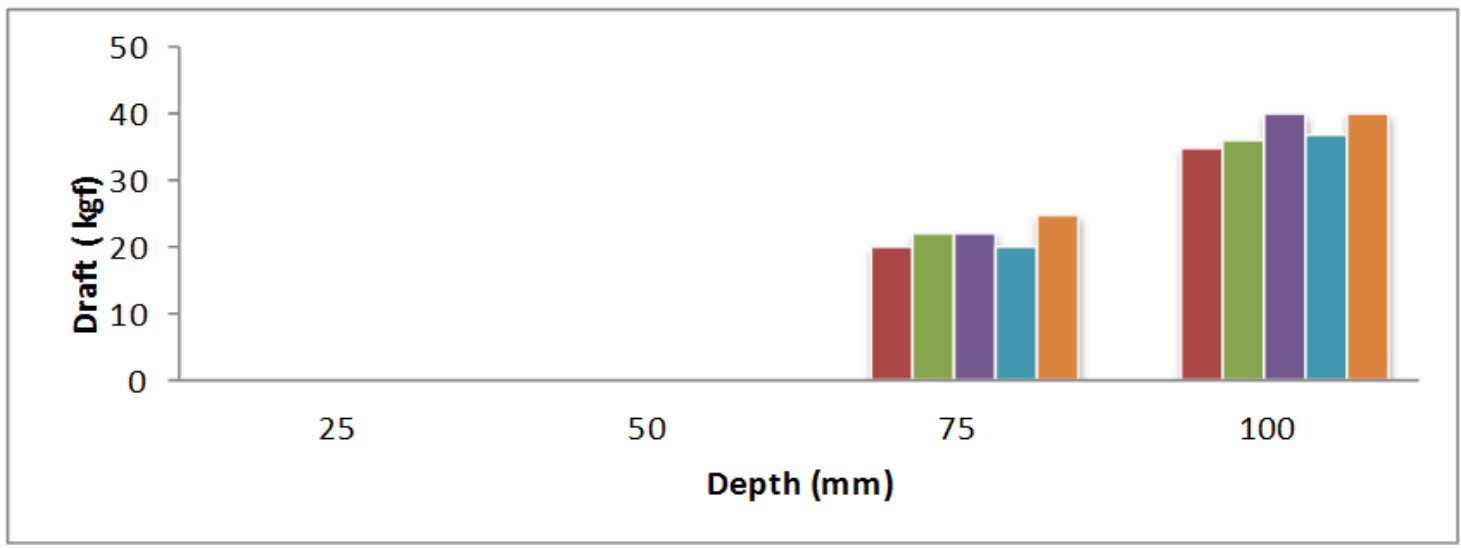

Fig.5 Effect of depth on soil disturbance for inverted ' $\mathrm{T}$ ' type furrow opener

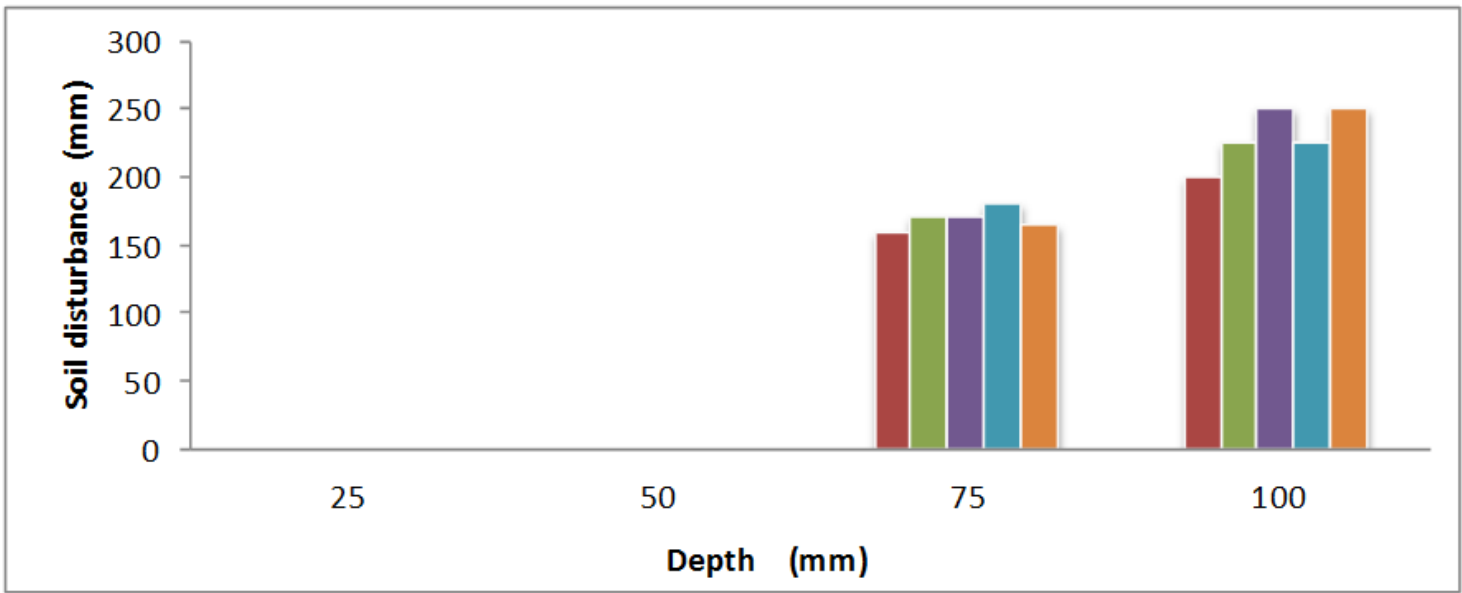

Fig.6 Effect of depth on draft for shovel type furrow opener

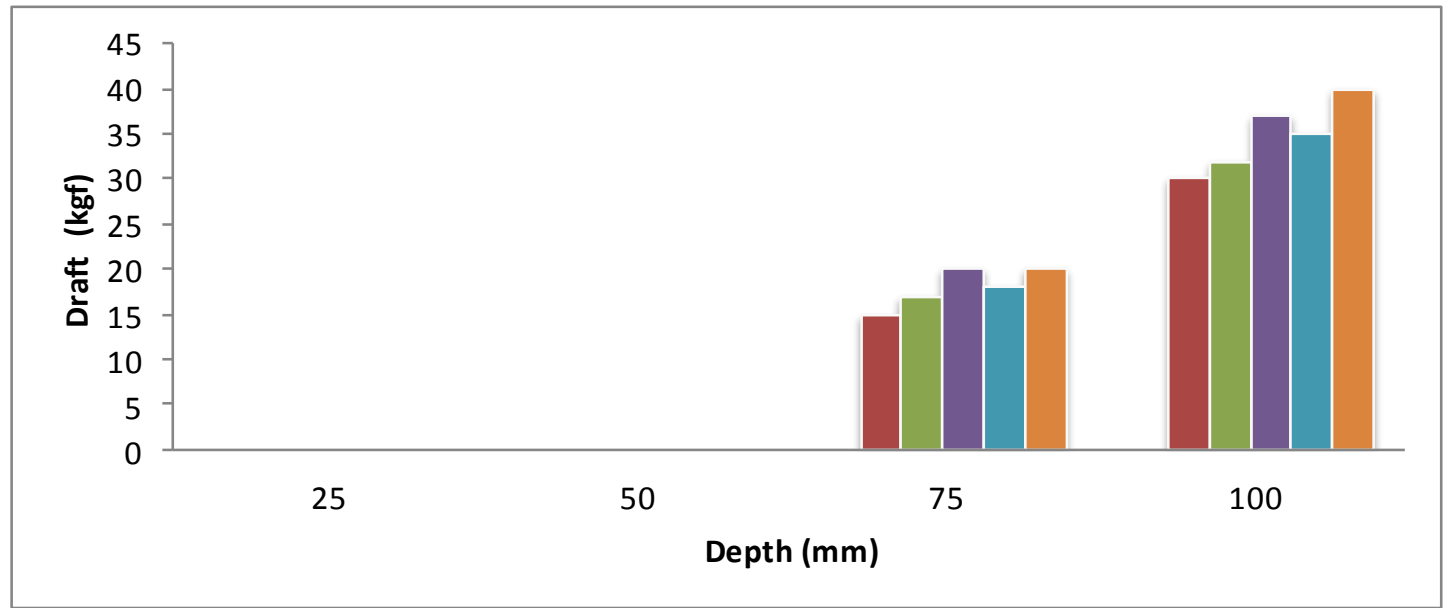


Fig.7 Effect of depth on soil disturbance for shovel furrow opener

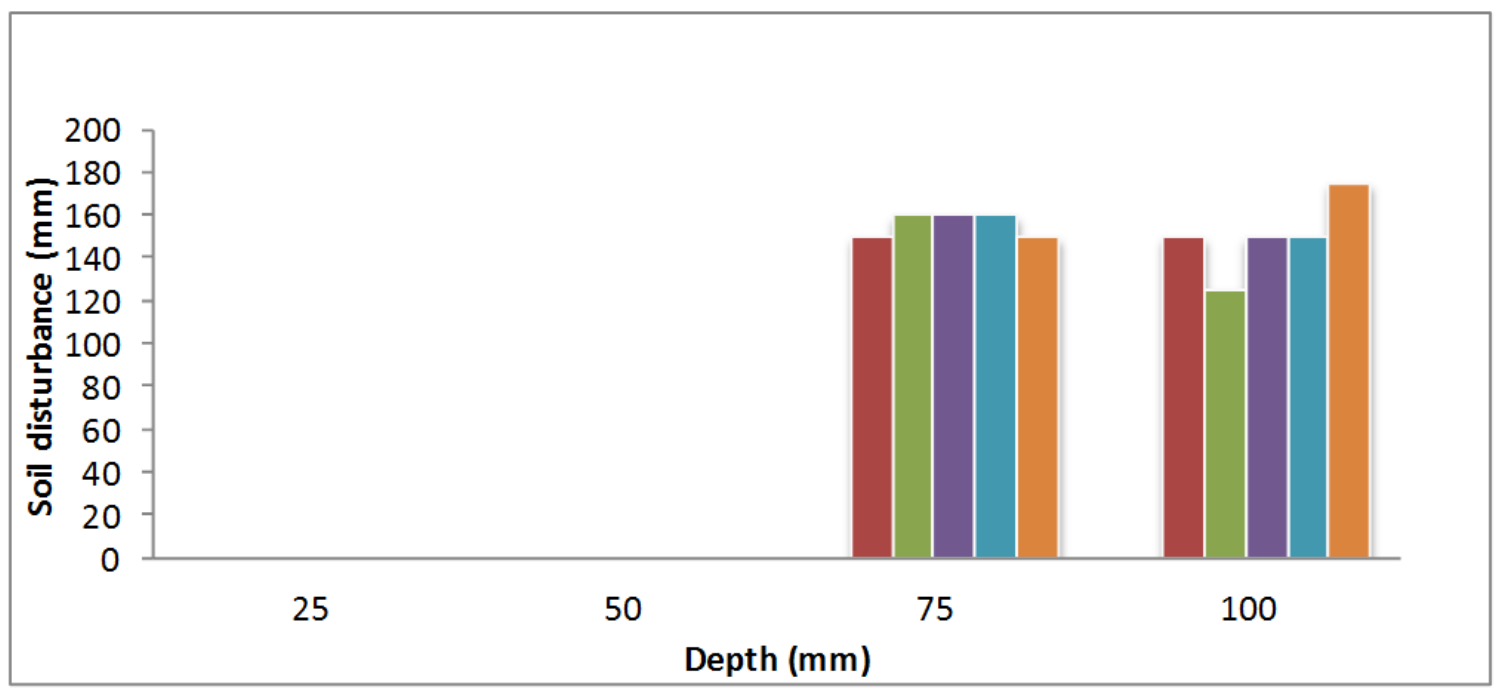

\section{Acknowledgements}

The authors hereby acknowledge the improvement brought about in this paper due to the valuable comments of editors and referee.

\section{References}

Chi, L. and Kushwaha, R. L. (1989). Finite element analysis of soil forces on different tillage tool shapes, ASAE, (891103): 17

Chowdhuri, D. (2001). Performance evaluation of various types of furrow openers on seed drills a review. Agricultural Engineering Research, 79(2):125-137.

Durant, D. M., Perumpral, J. and Desai, C. S. (1979). Soil bin test facility for soil tillage tool interaction studies, ASAE.

Dwyer, M. J. and Dawson, J. R. (1988). Improving the tractive performance of wheeled tractors in wet paddy fields. Proceedings of the $2^{\text {nd }}$ Asia Pacific conference of the International Society for Terrain Vehicle Systems, Bangkok, Thailand, 6-10. December 1988.

Gupta, J. P. and Pandey, K. P. (1991).
Performance of spiral and straight edge tynes of rotary tiller under wet land condition. Journal of Agricultural Engineering, 28(1-4): 211- 216.

Larson, D. L. and Clyma, H. E. (1995). Electro-osmosis effectiveness in reducing tillage draft force and energy requirements. ASAE, 38(5): 1281-1288.

Mathur, S. M. and Pandey, K. P. (1992). Influence of system parameters on the Performance of reversible hoe type furrow opener for animal drawn seed drills for lateritic sandy loam soil. Presented in Agriculture Engineering Conference held in Bangkok, Thailand on 7-10 December 1992, Vol-I:143-150.

Naderi-Boldaji M., Alimardani R., Sharifi A. and Tabatabaeefar A., (2009). Economical hand-pushed digital cone penetrometer. Int. Agrophysics, 23, 5560.

Sharma, D. N., Jain, M. L. and Sharma, S. (1996). Evaluation of no-tillage and Conventional tillage systems. Department of Agriculture Engineering, Haryana Agriculture University, Hisar, 125004, India.

Shen, S., Kitani, O., Okamoto, T., Yonekawa, S., Sakai, N. and Torii, T. (1993). 
Studies on minimum tillage tools (Part 2). Field experiments on tine implements, Japanese Society of Agricultural Machinery, 55(1): 23-31.

Stephens, L. E. and Johnson, R. R. (1991). Soil conditions created by planting systems. ASAE.
Tajuddin, A. and Balasubramanian, $\mathrm{M}$. (1995). Comparative performance evaluation of different types of furrow openers. Zonal Research Centre, College of Agricultural Engineering, Tamil Nadu Agricultural University, Coimbatore, 641 003, India.

\section{How to cite this article:}

Mithlesh Kumar, Ravi Baghel and Toman Parihar. 2017. Development of Soil Bin for Model Studies on Furrow Openers. Int.J.Curr.Microbiol.App.Sci. 6(12): 2899-2906. doi: https://doi.org/10.20546/ijcmas.2017.612.337 